\title{
De la allgemeine Religionswissenschaft a la realpolitik: potenciales aportes del humanismo de Eliade a la visión civilizatoria de Huntington
}

\author{
Eduardo Daniel Crespo Cuesta*
}

$\mathrm{E}$ ste artículo es un avance de la investigación llevada a cabo en el marco del proyecto: Del choque al diálogo: relaciones interculturales en el mundo globalizado, y en ese sentido, no pretende ser la exposición de un artículo concluido, sino una reflexión parcial.

Cuando en 1996 Samuel P. Huntington publicó El choque de civilizaciones y la reconfiguración del orden mundial, la discusión académica sobre el origen y naturaleza de los conflictos internacionales en el mundo pos Guerra Fría ya había comenzado. La postura de Huntington, de que el mundo había regresado a un estado donde los conflictos culturales y religiosos han sido la constante, mientras que los enfrentamientos ideológicos de la Guerra Fría constituyeron una notable excepción histórica, ha sido objeto de debates y críticas plenamente vigentes hasta el día de hoy.

La evolución de las tensiones internacionales vigentes, en especial la virulencia del fundamentalismo islámico y la fragilidad política del Medio Oriente, las consecuencias sociales de la reconfiguración demográfica de Europa o el ascenso de potencias como Rusia y China, hacen que la teoría propuesta por Huntington sea necesariamente tomada en cuenta (ya sea para justificarla, invalidarla o, más acertadamente, analizarla) al momento de buscar una interpretación más profunda que rebase los límites de una visión determinada por la geopolítica y el control de los recursos naturales. * Máster en Estudios Medievales, Universidad de Navarra, España. Profesor Investigador, Universidad de
los Hemisferios, Ecuador, «dcrespo@uhemisferios.edu.ec〉. 
Por supuesto, no se trata de negar la importancia de lo antedicho para la comprensión de la problemática civilizatoria actual. Ya que se trata de un fenómeno civilizatorio, tiene una dimensión cultural y religiosa que es necesaria considerar a fin de darle al objeto de estudio una mayor profundidad y complejidad, sin la cual más de una variable le serán esquivas al internacionalista que desee diseñar o pronosticar escenarios, tanto a nivel académico como político.

El término civilización puede significar muchas cosas. De entrada, exige la distinción entre civilización, concebida como lo contrario a la barbarie desde la Grecia clásica y retomada por los ilustrados franceses del siglo XVIII, y civilizaciones, en plural. Un reconocimiento tardío de una realidad pluricultural que se vio relegada por el auge de enfoques darwinianos y positivistas en las ciencias sociales desde el siglo XIX, y que sirvieron como justificación ideológica de las aventuras coloniales europeas desde ese siglo hasta el colapso de los imperios coloniales a mediados del siglo XX.

Como indica Huntington, al repasar diversos planteamientos teóricos sobre el concepto mismo de civilización, en última instancia hablar de civilizaciones implica dejar atrás la idea de que existe un único ideal civilizatorio. ${ }^{1}$ De hecho, es el primer paso a fin de abandonar una concepción eurocéntrica de la civilización o la cultura. Significa, entre otras cosas, la aceptación de un sistema internacional multicivilizatorio y que las sociedades humanas no se mueven en una línea de desarrollo única.

Los fenómenos culturales son indisociables de la condición humana, ya que se desarrollan en el marco de un conjunto de individuos. Por lo tanto, hablar de cultura o de civilización, es hablar de un fenómeno propio de las sociedades humanas. Como señala Huntington: “Tanto 'civilización' como 'cultura' hacen referencia a la forma global de vida de un pueblo, y una civilización es una cultura en mayúsculas". ${ }^{2}$ Las civilizaciones pueden ser concebidas como el grado más amplio de identidad cultural que tiene un individuo.

Dicho lo anterior, se puede observar que existe una relación sistémica entre civilización, culturas, sociedades e individuos. Las civilizaciones son en-

1. Sobre: "El concepto de civilización...", ver: Samuel Huntington, El choque de civilizaciones y la reconfiguración del orden mundial (Barcelona: Paidós, 2005).

2. Huntington, "El choque de civilizaciones y la reconfiguración del orden mundial". 
tes dinámicos, históricos: "La historia humana es la historia de las civilizaciones". ${ }^{3}$ Por ende, las civilizaciones nacen, evolucionan, pueden expandirse, atrofiarse y también desaparecer. Las civilizaciones trascienden un idioma, o una etnia, o un sistema político o económico determinado, ya que, como fue previamente señalado, son las entidades culturales más amplias en las cuales clasificar al género humano.

La manera en que idiomas, etnias, sistemas políticos o económicos interactúan varía de una civilización a otra, pero en lo que parece existir un consenso académico, es que en la mayoría de civilizaciones, el elemento que las define históricamente con más fuerza es la religión. ${ }^{4}$ En efecto, si hacemos un breve repaso por las civilizaciones más importantes del mundo contemporáneo: la civilización china (o sínica, para ser más exactos), cuenta con el confucianismo (aunque es, en sentido estricto, más bien un sistema ético y filosófico); la civilización japonesa, vástago de la anterior, con el sintoísmo; la hindú, la islámica o la ortodoxa, de hecho son nombradas en relación con la religión que les dio forma.

En este sentido, la civilización occidental representa un caso particular: ${ }^{5}$ como indica Royal, el término occidental no tiene larga data, pues empezó a utilizarse apenas a inicios del siglo XX ${ }^{6}$ La civilización occidental contemporánea es una civilización cuyo elemento de definición más importante ya no es exclusivamente la religión. La mayoría de académicos concuerdan en que, como lo menciona Kurth, la civilización occidental está conformada, en términos amplios, por tres tradiciones fundamentales: la cultura clásica (Grecia y Roma), el cristianismo (entiéndase el cristianismo occidental, tanto en su variante católica como protestante), y la Ilustración.

3. Ibíd.

4. Uno de los planteamientos más originales al estudio de las civilizaciones, desde el ámbito hispanoamericano, es del chileno Erik Haindl. Ver: Erik Haindl, Las civilizaciones y las leyes de la historia (Santiago de Chile: Universidad Gabriela Mistral, 2011).

5. Para una breve clasificación de las civilizaciones, tanto históricas como contemporáneas, ver: Huntington, "El choque de las civilizaciones y la reconfiguración del orden mundial", 53-58.

6. ¿De dónde viene la civilización "occidental"? El término no hace referencia a una simple ubicación geo gráfica, y no existía hasta hace relativamente poco. De acuerdo con el Oxford English Dictionary, Chesterton fue el primero en utilizar la expresión "hombre occidental" apenas noventa años atrás, en 1907. Traducción del autor. Robert Royal. "Who Put the West in Western Civilization? ", The Intercollegiate Review (Spring 1998): 3-17. 
Donde existen discrepancias es en la manera de interpretar cómo interactúan estas tres tradiciones entre sí, y la forma en que dicha interacción afecta al ser mismo de la civilización occidental. En este sentido, la relación, casi siempre conflictiva, entre el pensamiento ilustrado (sería más adecuado hablar del pensamiento ilustrado radical) y el cristianismo; y en menor medida, entre la Ilustración y la cultura clásica, ha traído consecuencias especialmente significativas y vigentes hasta el día de hoy. ${ }^{7}$

Aunque la postura de Huntington valora lo cultural como una variable significativa para el análisis del sistema internacional, en mi opinión no alcanza todo su potencial al verse limitada por un presupuesto teórico que es, en última instancia, su motivación principal: el reconocimiento de dichas diferencias civilizatorias como insalvables, y su utilización como una herramienta de política exterior para el afianzamiento de la hegemonía de los Estados Unidos:

Los conflictos locales con mayores probabilidades de convertirse en guerras más amplias son los existentes entre grupos y Estados procedentes de civilizaciones diferentes. Los modelos predominantes de desarrollo político y económico difieren de una civilización a otra. Las cuestiones clave de la agenda internacional conllevan diferencias entre civilizaciones. El poder se está desplazando, de Occidente, predominante durante largo tiempo, a las civilizaciones no occidentales. La política global se ha vuelto multipolar y multicivilizacional. ${ }^{8}$

Lo mejor de la teorización de Huntington se aprecia en su clasificación y descripción de los conflictos entre civilizaciones, para lo cual es prolijo en ejemplos muy bien desarrollados:

Los conflictos intercivilizatorios adoptan dos formas. En el plano particular o micronivel, los conflictos de línea de fractura se producen entre Estados vecinos pertenecientes a civilizaciones diferentes, entre grupos de diferentes civilizaciones dentro de un Estado, y entre grupos que, como en las antiguas Unión Soviética y Yugoslavia, están intentando crear nuevos Estados a partir de las ruinas de otros viejos. Los conflictos de línea de fractura predominan de forma particular entre musulmanes y no musulmanes [...]. En el plano mundial o universal, los conflictos de Estados centrales se producen entre los grandes Estados de diferentes civilizaciones. ${ }^{9}$

7. James Kurth. "Western civilization, our tradition". The Intercollegiate Review, No. 39 (2003): 5-13.

8. Huntington, "El choque de civilizaciones y la reconfiguración del orden mundial".

9. Ibíd. 
Huntington le dedica dos capítulos completos a la descripción de los conflictos de línea de fractura: entre sus características generales se puede apreciar que hunden sus raíces en diferencias históricas profundas, que afectan directamente a la identidad grupal de los bandos enfrentados. En consecuencia, son conflictos prolongados en el tiempo, casi interminables, y cuando estalla una guerra, la misma no suele resolverse ni en el corto plazo ni con facilidad; suele estar jalonada por altos el fuego frecuentemente violados, armisticios y acuerdos parciales, pero muy difícilmente por acuerdos de paz globales. Casi siempre la intervención de terceros actores es la única manera de llegar a una negociación efectiva. Por su condición de guerras, donde la identidad es el factor en juego más valioso, suelen ser particularmente cruentas, llenas de episodios atroces y violaciones masivas de los derechos humanos; la victoria militar de uno de los bandos incrementa las posibilidades de un genocidio o de un desplazamiento masivo de población.

Se trata de conflictos en última instancia de naturaleza cultural, civilizatoria; y, debido al papel que juega la religión en la definición misma de lo que constituye una civilización, casi siempre se trata de guerras entre grupos de distintas religiones:

[D]ado que la religión es la principal característica definitoria de las civilizaciones, las guerras de línea de fractura se producen casi siempre entre pueblos de religiones diferentes. Algunos analistas restan importancia a este factor. Indican, por ejemplo, la etnia y la lengua comunes, la pacífica convivencia del pasado y los abundantes matrimonios mixtos de serbios y musulmanes en Bosnia, y rechazan el factor religioso haciendo referencias al «narcisismo de las pequeñas diferencias» de Freud. Sin embargo, este juicio se enraíza en una miopía prolongada. Milenios de historia humana han demostrado que la religión no es una «pequeña diferencia», sino posiblemente la diferencia más profunda que puede existir entre la gente. La frecuencia, intensidad y violencia de las guerras de línea de fractura quedan enormemente intensificadas por las creencias en dioses diferentes. ${ }^{10}$

Lo antedicho puede ser considerado, a pesar de su innegable calidad teórica y descriptiva, como una oportunidad perdida. Al subordinar una sugerente aproximación a la relación entre civilizaciones y política exterior, entre culturas y ejercicio del poder, a una visión neorrealista de las relaciones internacionales (en cuanto a las filiaciones religiosas son trans estatales y existen

10. Ibíd., 344. 
grupos religiosos que pueden actuar como actores del sistema internacional de pleno derecho), el aporte de los estudios humanísticos queda relegado a un accesorio que justifica, mas no profundiza: un aporte interdisciplinar cosmético, sin más.

Este es un lujo que el estudioso de las relaciones internacionales no puede seguir permitiéndose, más aun cuando décadas de análisis concentrados en lo político o lo económico han dado resultados ineficaces o claramente errados.

La profundidad y complejidad de las relaciones entre distintas civilizaciones ya no pueden verse simplemente en un mapa político. La revolución de las tecnologías de la información, el aceleramiento asimétrico de la globalización y el fenómeno migratorio actual, el más importante de la historia humana, han cambiado y siguen cambiando el mapa cultural, religioso y demográfico mundial, sobre todo en las naciones occidentales. Las líneas de fractura ya no se aprecian solamente en una frontera entre grupos étnicos, Estados o bloques, podemos verlas ahora entre una barriada u otra de Londres o Bruselas.

Esta necesidad de un aporte real desde otras disciplinas no es nueva, aunque ahora se presente como imperiosa frente al escenario actual. De las diversas aproximaciones posibles, esta investigación busca centrarse en el trabajo y contribuciones del pensador, literato e investigador rumano Mircea Eliade, uno de los más grandes historiadores de la religión del siglo XX. ${ }^{11}$

Nacido en Bucarest en 1907, se licenció en Filosofía en 1928 poco antes de partir a la India, donde vivió hasta fines de 1931, este periodo lo marcó profundamente y sus trabajos sobre la espiritualidad india lo posicionaron años después como uno de los mayores orientalistas de su generación.

A su regreso a Rumania se involucró activamente en la agitada vida cultural y política de la llamada joven generación, siendo una de sus cabezas y miembro del grupo Criterion. En 1933 se doctoró en Filosofía por la Universidad de Bucarest y su actividad política aumentó. Durante esta etapa ingresó

11. Al concentrarse en los potenciales aportes que, desde el pensamiento de Mircea Eliade, podrían hacerse al debate actual sobre el choque y diálogo entre civilizaciones, el artículo no pretende desconocer las críticas que se han hecho a la teorización de Huntington, como las del palestino-estadounidense Edward Said, en su ensayo The Clash of ignorance, del año 2001, o las del ex presidente iraní Mohammad Khatami, quien impulsó a escala internacional el concepto de diálogo entre civilizaciones. El objetivo de profundizar en el pensamiento de Eliade es demostrar que ahonda en el concepto del diálogo desde una especialización distinta, lo que podría resultar en conclusiones sugerentes y complementarias a las que han venido elaborándose desde otras perspectivas. 
en la Guardia de Hierro y mantuvo una posición ambigua ante el ascenso del antisemitismo en Rumania. Sus actitudes políticas de esta época terminaron siendo taras de las que intentó desligarse posteriormente, aunque nunca tomó una posición crítica ante este aspecto de su pasado; esto fue objeto de acusaciones futuras de las que jamás pudo desligarse satisfactoriamente.

Durante la Segunda Guerra Mundial fue Agregado Cultural en Londres y en Lisboa, y en 1942 realizó su último viaje a Rumania. Entre 1945 y 1957 vivió en París, donde escribió algunos de sus más importantes trabajos y empezó a ganar renombre como intelectual y literato. En 1950 ingresó en el Círculo de Eranos, en el que participará hasta 1969, salvo contadas ocasiones. Esto le permitió entrar en contacto con intelectuales de la talla de Carl Gustav Jung, Gerardus Van der Leeuw, Louis Massignon, Joachim Wach o Gershom Scholem, entre otros. ${ }^{12}$

A mediados de los años cincuenta su vinculación con la Universidad de Chicago le abrió las puertas del mundo académico estadounidense: desde 1957, ejerció como profesor titular en la misma y su obra empezó a ser reconocida fuera de Europa. En 1963 apareció la primera monografía dedicada a su trabajo: Mircea Eliade y la dialéctica de lo sagrado, de su colega Thomas J. Altizer.

Fueron décadas de maduración intelectual y de consolidación como uno de los grandes pensadores del siglo XX: desde mediados de la década de los sesenta hasta su muerte, recibió un sinnúmero de reconocimientos y homenajes en los Estados Unidos, Europa y Argentina, incluyendo la propuesta, infructuosa, de la Universidad de Lyon de su candidatura al premio Nobel de Literatura (1980). En 1985 la Universidad de Chicago otorgó el nombre de Mircea Eliade a la cátedra de Historia de las Religiones: fue la primera vez que una cátedra de dicha universidad recibió el nombre de una persona viva.

El 22 de abril de 1986, Eliade murió en Chicago, y los homenajes y congresos en su nombre se extendieron hasta fines de esa década. A su plena vigencia en el mundo académico entre los años sesenta y ochenta del siglo pasado (en áreas tan distintas como la filosofía, la filología, la antropología,

12. El Círculo de Eranos, vigente entre los años 1933 y 1988 (el nuevo Eranos, iniciado en 1989, no tiene los alcances ni el impacto del periodo original) reunió a intelectuales como los antedichos, a los que se puede sumar nombres como los de Heinrich Zimmer, Ernst Benz, Joseph Campbell, Henry Corbin, Pierre Hadot o Karl Kérenyi, entre algunas decenas más (casi 150). 
la psicología profunda, la fenomenología o la historia de las religiones), se debe añadir su posterior redescubrimiento como un literato original y prolífico. Todo esto, como lo menciona Joan B. Llinares, demuestra la plena vigencia de Eliade como historiador de las religiones y escritor, y la utilidad de su pensamiento y obra frente a las problemáticas propias de nuestro tiempo. ${ }^{13}$

Para Eliade, lo religioso ocupa el núcleo de la experiencia humana. Más allá de sus particularidades históricas, su hermenéutica de lo sagrado busca develar lo universal detrás del fenómeno religioso, su esencia transhistórica. Por ejemplo, al describir su metodología de trabajo para interpretar el aspecto simbólico del templo de Borobudur, señala que: "Esta obra no se inserta en la serie de libros modernos de filosofía de la cultura, pues no parte del estudio morfológico de una cierta cultura ni examina los estilos culturales, sino que busca demostrar la universalidad de las tradiciones metafísicas y la unidad del simbolismo de las primeras civilizaciones humanas". ${ }^{14}$

Para él, la permanencia de lo sagrado, propia del Homo religiosus, sigue generando valores culturales y moldeando comportamientos, más allá del nivel de creencia o no de una persona, o de secularización de una sociedad como un todo:

[E]l hombre arreligioso en estado puro es un fenómeno más bien raro, incluso en la más desacralizada de las sociedades modernas. La mayoría de los hombres «sin religión» se siguen comportando religiosamente, sin saberlo. No solo se trata de la masa de «supersticiones» o de «tabúes» del hombre moderno, que en su totalidad tienen una estructura o un origen mágico-religioso. Hay más, el hombre moderno que se siente y pretende ser arreligioso dispone aún de toda una mitología camuflada y de numerosos ritualismos degradados. Como hemos mencionado, los regocijos que acompañan al año nuevo o a la instalación en una nueva casa presentan, en forma laica, la estructura de un ritual de renovación. Se descubre el mismo fenómeno en el caso de las fiestas y alborozos que acompañan al matrimonio o al nacimiento de un niño, a la obtención de un nuevo empleo, de una promoción social, etc. Se podría escribir todo un libro sobre los mitos del hombre moderno $[\ldots] \cdot{ }^{15}$

13. Ver la introducción de Llinares al volumen conjunto Mircea Eliade, el profesor y el escritor. Consideraciones en el centenario de su nacimiento, 1907-2007. Al igual que en el caso anterior, es pertinente señalar que dicho texto es uno de los pocos trabajos en castellano dedicados a la obra de Eliade como un todo y que trata de reposicionarlo en el ámbito académico hispanoamericano: Joan B. Llinares, "Introducción”. En Mircea Eliade, el profesor y el escritor. Consideraciones en el centenario de su nacimiento, 1907-2007 (Valencia: Pre-textos, 2007): 7-12.

14. Mircea Eliade. Erotismo místico en la India (Barcelona: Editorial Kairós, 2002).

15. Mircea Elialde. Lo sagrado y lo Profano (Barcelona: Paidós, 2014). 
Eliade en varios de sus trabajos se centra en los aspectos culturales de esta continuidad, en cómo los rituales sociales modernos, aunque desacralizados, mantienen no solo su origen religioso sino que representan una nueva dimensión de la búsqueda de lo sagrado, aunque la misma casi siempre se mantenga en el plano de lo inconsciente: aún degradados por la laicidad, los mitos primigenios siguen siendo generadores de cultura y por ende de comportamientos ligados al aspecto más íntimo del fenómeno civilizatorio: el religioso. ${ }^{16}$

La relevancia de lo antedicho no se refleja simplemente en aspectos sociales que pudiesen ser considerados secundarios, ya que esta aproximación es válida para el análisis de las estructuras sociales, jurídicas y políticas que conforman a las sociedades modernas, más allá de las laicas (desacralizadas sería un término más adecuado) que las mismas puedan llegar a considerarse. El traslado de contenidos míticos de la esfera de lo sagrado al espacio político, por ejemplo, en los países occidentales, se evidencia con claridad en la ritualidad y pseudo sacralidad que acompañan a los mitos fundacionales del Estado, sus símbolos, sus padres fundadores o sus fiestas patrias; sin una historia sagrada que lo legitime, pareciese que un Estado carecería de un elemento constitutivo esencial sobre el cual asentarse y justificar su misma existencia. ${ }^{17}$

Cuando se comprenden las raíces religiosas del nacionalismo, se aclara el panorama para comprender la fuerza de los contenidos subjetivos que han

16. Fernando Schwarz señala y destaca el redescubrimiento del factor espiritual frente al racionalismo clásico en el estudio de la evolución humana, rebasando la interpretación tradicional de la revolución neolítica (basada en las necesidades materiales) a la luz de los últimos descubrimientos arqueológicos. Ver: Fernando Schwarz. Mitos, ritos y símbolos. Antropología de los sagrado (Buenos Aires: Biblos, 2008). El también rumano Emil Cioran, amigo íntimo de Eliade durante casi toda su vida y uno de los pensadores más relevantes del siglo XX, aunque desde una perspectiva diferente, desengañada y duramente crítica con lo religioso, no dejó de reconocer el papel fundamental de la búsqueda de lo sagrado, de lo absoluto, en el centro mismo de las preocupaciones humanas. Respecto al marxismo, la ideología política atea por excelencia, señala que: "Al divinizar la historia para desacreditar a Dios, el marxismo sólo ha conseguido volver a Dios más extraño y más obsesionante. Todo se puede sofocar en el hombre, salvo la necesidad de absoluto, que sobrevivirá a la destrucción de los templos, e incluso a la desaparición de la religión sobre la tierra". Ver: Emil M. Cioran. Historia y Utopía (Barcelona: Tusquets, 2011).

17. Sin llegar a una profundización exhaustiva, piénsese en el valor cívico que tienen en una sociedad su bandera, escudo e himno nacionales; el carácter mesiánico de sus padres fundadores y la importancia de conmemorar periódicamente fundaciones, batallas, independencias. Actos tales como la jura a la bandera o las ceremonias realizadas ante las tumbas de héroes (caudillos, soldados desconocidos, etc.) mantienen una ritualidad religiosa fácilmente reconocible. Inclusive la utilización de nombres como templo de la patria o altar patrio, ya sea respecto a monumentos concretos o de manera figurada, refleja con claridad la proyección de contenidos subjetivos desde el espacio de lo sagrado a la esfera de lo simbólico detrás de la identidad del Estado laico. 
sido trasladados a esta nueva identidad laica; y a más palpable es la identidad religiosa, más nítido es el carácter profundo detrás de los conflictos civilizatorios, empatando así con la visión planteada por Huntington.

Es en este punto donde el pensamiento de Eliade alcanza su mayor importancia respecto al análisis de los conflictos civilizatorios que azotan al mundo contemporáneo. Para él, la historia de las religiones no es una ciencia de segundo orden o auxiliar; se trata de una disciplina total que, de alcanzar su potencial, abriría al hombre las puertas de un nuevo humanismo, capaz de romper con las aparentemente insalvables fronteras entre civilizaciones. Esta preocupación, manifestada en sus trabajos académicos, también se encuentra presente en sus textos literarios o autobiográficos. Al referirse a la irrupción de los pueblos que desde mediados del siglo XX empezaron a pugnar para dejar de ser objetos pasivos de la Historia y constituirse en sujetos activos de la misma, a la par de la civilización occidental, Eliade menciona:

Un verdadero diálogo debe abordar los valores centrales de las culturas de quienes dialogan. Ahora bien, para entender estos valores correctamente es necesario conocer sus fuentes religiosas, pues, como ya sabemos, las culturas no europeas, tanto orientales como «primitivas», todavía siguen nutriéndose de un fértil suelo religioso. Por esta razón creemos que la historia de las religiones está destinada a desempeñar un papel importante en la vida cultural contemporánea. Y esto no es así únicamente por el hecho de que una comprensión de las religiones exóticas y arcaicas ayude de forma significativa a un diálogo cultural con los representantes de dichas religiones, sino que también, al intentar entender las situaciones existenciales expresadas por los documentos que estudia, el historiador de las religiones accede inevitablemente a un conocimiento más profundo del ser humano. Es en base a este conocimiento como puede desarrollarse un nuevo humanismo a escala mundial. [...] [A]l estudiar las expresiones religiosas de una cultura, el investigador la aborda desde dentro, y no meramente en su contexto sociológico, económico y político. ${ }^{18}$

Lo anterior le da un sentido más profundo a aquella frase de Huntington de que "la política global se ha vuelto multipolar y multicivilizacional", citada líneas arriba, haciendo énfasis en lo segundo y abriendo la puerta a una aproximación que si bien señala, Huntington no llega a desarrollar en su plenitud. Hasta aquí, los avances de mi investigación. Espero que mis estudios en curso profundicen en estos conceptos y planteen nuevas líneas de trabajo a fin de

18. Elialde, "La búsqueda, Historia y sentido de las Religiones". 
que el nuevo humanismo propuesto por Eliade demuestre su utilidad y vigencia en el presente escenario político mundial.

En el punto en que las cosas se encuentran, solo merecen interés las cuestiones de estrategia y de metafísica, aquellas que nos limitan a la historia y las que nos apartan de ella: la actualidad y el absoluto, los periódicos y los Evangelios... Vislumbro el día en que ya solo leeremos cables telegráficos y plegarias. ${ }^{19}$

\section{Bibliografía}

Cioran, Emil M. Historia y utopía. Barcelona: Tusquets, 2011.

Eliade, Mircea. Erotismo mistico en la India. Barcelona: Editorial Kairós, 2002.

—. La búsqueda. Historia y sentido de las religiones. Barcelona: Kairós, 2008.

- Lo sagrado y lo profano. Barcelona: Paidós, 2014.

Haindl, Erik. Las civilizaciones y las leyes de la historia. Santiago de Chile: Universidad Gabriela Mistral, 2011.

Huntington, Samuel. El choque de civilizaciones y la reconfiguración del orden mundial. Barcelona: Paidós, 2005.

Kurth, James. "Western civilization, our tradition". The Intercollegiate Review (Fall 2003/ Spring 2004): 5-13.

Llinares, Joan B. "Introducción”. En Joan B. Llinares, Salvador Cuenca, Carlos García García y otros, Mircea Eliade, el profesor y el escritor. Consideraciones en el centenario de su nacimiento, 1907-2007, 7-12. Valencia: Pre-Textos, 2007.

Royal, Robert. "Who Put the West in Western Civilization?". The Intercollegiate Review (Spring 1998): 3-17.

Schwarz, Fernando. Mitos, ritos, símbolos. Antropología de lo sagrado. Buenos Aires: Biblos, 2008. 